\title{
The structure of sodium trisilicate glass via molecular dynamics employing three-body potentials
}

\author{
R. G. Newell, B.P. Feuston, and S. H. Garofalini \\ Department of Ceramic Engineering, Rutgers University, Piscataway, New Jersey 08855-0909
}

(Received 17 June 1988; accepted 21 October 1988)

\begin{abstract}
Molecular dynamics simulations (MD) employing multibody potentials were used to simulate sodium trisilicate glass $\left(\mathrm{Na}_{2} \mathrm{O} \cdot 3 \mathrm{SiO}_{2}\right)$. A multibody term has been added to a pair potential in order to incorporate the bond directionality which is expected for the partially covalent silicate structure. The structure of the glass was analyzed and results were compared to those found using two-body potentials and molecular statics, as well as to experimental results found using X-ray diffraction, XPS, NMR, and EXAFS. Current results compared favorably to experiment and showed improvement over results obtained using two-body potentials. Nearest neighbor distances and coordination numbers agreed well with published data. Although two-body potentials normally show overcoordinated silicon $(>4.3)$ and broad $\mathrm{O}-\mathrm{Si}-\mathrm{O}$ tetrahedral angle distributions, in this study all silicon exhibited tetrahedral coordination (4.0) and the $\mathrm{O}-\mathrm{Si}-\mathrm{O}$ bond angle distribution was markedly sharpened. The number of nonbridging oxygens was shown to be nearly equal to the number of sodium ions present, and a reasonable distribution of $Q_{i}$ species was found. The overall structure closely resembled the modified network structure of glass proposed experimentally, with silicon tetrahedra remaining intact and sodium ions breaking up the network through the creation of nonbridging oxygens.
\end{abstract}

\section{INTRODUCTION}

Molecular dynamics (MD) computer simulations have been used rather extensively to simulate the structure of silica and silicate glasses. ${ }^{1-8}$ Many of these studies have focused on alkali silicates ${ }^{1,4-7}$ and sodium silicates ${ }^{1,5-7}$ in particular. Until recently most MD simulations have used effective two-body potentials as the basis of atomic interactions. ${ }^{1-7}$ Although simulation results have reasonably agreed with those found experimentally, ${ }^{10-23}$ this approach is sometimes criticized because the pair potential does not take into consideration the partial covalency which is normally associated with the silica structure. Feuston and Garofalini ${ }^{8}$ have recently developed a three-body potential that introduces bond directionality in the vitreous silica structure. The three-body potential acts to restrict the deviation of the tetrahedral angle, $\phi_{\mathrm{O}-\mathrm{Si}-\mathrm{O}}$, from its theoretically expected value of $109.5^{\circ}$. The three-body potential is discussed extensively by Feuston and Garofalini in the MD study of silica glass. ${ }^{8}$

The purpose of this study was to examine the applicability of the three-body potential to sodium silicate glass. The glass structure obtained using this new empirical threebody potential has been analyzed and results have been compared with those found using two-body potentials, ${ }^{1-7}$ as well as those found through various experimental means including X-ray diffraction, ${ }^{10-14}$ XPS, ${ }^{18,19}$ EXAFS, ${ }^{15,16}$ neutron scattering, ${ }^{17}$ and NMR. ${ }^{20-23}$

Section II outlines the computational procedure used in these MD simulations. Section III presents the results and discussion thereof including subsections on general structure (III.A), coordination (III.B), the bridging to non- bridging oxygen ratio (III.C), and $Q$ species distribution (III.D). A summary follows in Sec. IV.

\section{COMPUTATIONAL PROCEDURE}

A modified form of the Born-Mayer-Huggins (BMH) two-body potential was used to describe interactions between pairs of atoms, $i$ and $j$, separated by a distance $r_{i j}$ as follows:

$$
\phi_{i j}=A_{i j} \exp \left(\frac{-r_{i j}}{\rho}\right)+\frac{Z_{i} Z_{j} e^{2}}{r_{i j}} \operatorname{erfc}\left(\frac{r_{i j}}{\beta_{i j}}\right)
$$

where $r_{i j}$ is the distance between atoms $i$ and $j, q_{i}$ is the formal ionic charge, and $A_{i j}, \rho$, and $\beta_{i j}$ are constants. Details of the terms in this potential, especially with respect to the usage of the $\beta_{i j}$ term, have been presented previously. ${ }^{24,25}$ Briefly, $A_{i j}$ is used to obtain the appropriate cation-anion bond distance. The $\beta_{i j}$ term, rather than being the normal size dependent-species independent convergence term within the complementary error function, is a constant for cation-anion pairs, cation-cation pairs, and anion-anion pairs and is size independent.

In addition to the BMH potential, a three-body contribution at central atom $i$ and near neighbors $j$ and $k$ was introduced according to the following form:

$$
\begin{aligned}
& h\left(r_{i j}, r_{i k}, \theta_{j i k}\right)=\lambda_{i} e^{\left(\gamma_{i}\left(r_{i j}-r_{i}^{c}\right)+y_{i}\left(r_{i k}-r\right)\right.}\left(\cos \theta_{j i k}+\frac{1}{3}\right)^{2} ; \\
& \text { if } r_{i j}<r_{i}^{c} \text { or } \quad r_{i k}<r_{i}^{c} \\
& h\left(r_{i j}, r_{i k}, \theta_{j i k}\right)=0 ; \quad \text { if } r_{\mathrm{ij}} \geqslant r_{i}^{c} \quad \text { or } \quad r_{i k} \geqslant r_{i}^{c}
\end{aligned}
$$

where $\cos _{j i k}=$ angle subtended by $r_{i j}$ and $r_{i k}$ with vertex at $i$, and $\lambda_{i}, \gamma_{i}$, and $r_{i}^{c}$ are constants. Additional details concern- 
ing this potential are discussed by Feuston and Garofalini. ${ }^{8}$ The parameters used in formulations (1) and (2), given in Table I, were taken from a set which gave good results for bulk silica during the parameter search for that system. Since the intent of the current study is to determine the applicability of this potential, which works well for silica, to simulate sodium silicate, no reparameterization occurred.

A bulk $\mathrm{Na}_{2} \mathrm{O} \cdot 3 \mathrm{SiO}_{2}$ glass of 384 atoms was simulated using periodic boundary conditions in three dimensions with an appropriate volume for sodium trisilicate glass. ${ }^{26}$ The starting configuration was taken from a previous study, ${ }^{5}$ the only change being the introduction of the three-body potential between atoms and constant $\beta_{i j}$ values for species pairs. A $3000 \mathrm{~K}$ melt was brought to equilibrium at room temperature over a total time period of $30 \mathrm{ps}$, reaching equilibrium at $3000 \mathrm{~K}, 1500 \mathrm{~K}$, and $300 \mathrm{~K}$. At each temperature throughout cooling, velocities were rescaled for the first 2.5 ps of each run and then continued at constant energy for the next 7.5 ps. The MD time step used was $1.0 \times 10^{-3} \mathrm{ps}$.

\section{RESULTS AND DISCUSSION}

\section{A. General structure}

The structure of the simulated sodium trisilicate glass was determined through the use of the radial distribution function (RDF), bond angle distribution, and coordination number analysis. The RDF in Fig. 1 indicates distinct local order without long-range order, which is characteristic for glasses. Nearest neighbor distances and coordination numbers were calculated for each atomic pair and appear in Table II along with those reported from other simulations and experimental techniques. Each silicon was tetrahedrally coordinated with exactly 4.0 oxygen at a $\mathrm{Si}-\mathrm{O}$

TABLE I. Parameters used in potential equations.

\begin{tabular}{ll}
\hline \hline Parameter & Value \\
\hline$A_{\mathrm{Si}-\mathrm{Si}}$ & $1.8770 \times 10^{-16} \mathrm{~J}$ \\
$A_{\mathrm{Si-O}}$ & $2.9620 \times 10^{-16} \mathrm{~J}$ \\
$A_{\mathrm{Si-Na}}$ & $2.0013 \times 10^{-16} \mathrm{~J}$ \\
$A_{\mathrm{O}-\mathrm{O}}$ & $0.7254 \times 10^{-16} \mathrm{~J}$ \\
$A_{\mathrm{O}-\mathrm{Na}}$ & $3.1954 \times 10^{-16} \mathrm{~J}$ \\
$A_{\mathrm{Na}-\mathrm{Na}}$ & $2.1590 \times 10^{-16} \mathrm{~J}$ \\
$\beta_{\mathrm{Si}-\mathrm{Si}}$ & $2.30 \AA$ \\
$\beta_{\mathrm{Si}-\mathrm{O}}$ & $2.34 \AA$ \\
$\beta_{\mathrm{Si}-\mathrm{Na}}$ & $2.30 \AA$ \\
$\beta_{\mathrm{O}-\mathrm{O}}$ & $2.28 \AA$ \\
$\beta_{\mathrm{O}-\mathrm{Na}}$ & $2.34 \AA$ \\
$\beta_{\mathrm{Na}-\mathrm{Na}}$ & $2.30 \AA$ \\
$\lambda_{\mathrm{Si}}$ & $24.0 \times 10^{-18} \mathrm{~J}$ \\
$\lambda_{\mathrm{O}}$ & $1.00 \times 10^{-18} \mathrm{~J}$ \\
$\lambda_{\mathrm{Na}}$ & 0.0 \\
$\gamma_{\mathrm{Si}}$ & $2.60 \AA$ \\
$\gamma_{\mathrm{O}}$ & $2.00 \AA$ \\
$r_{\mathrm{Si}}^{c}$ & $3.00 \AA$ \\
$r_{\mathrm{O}}^{c}$ & $2.60 \AA$ \\
& \\
\hline
\end{tabular}

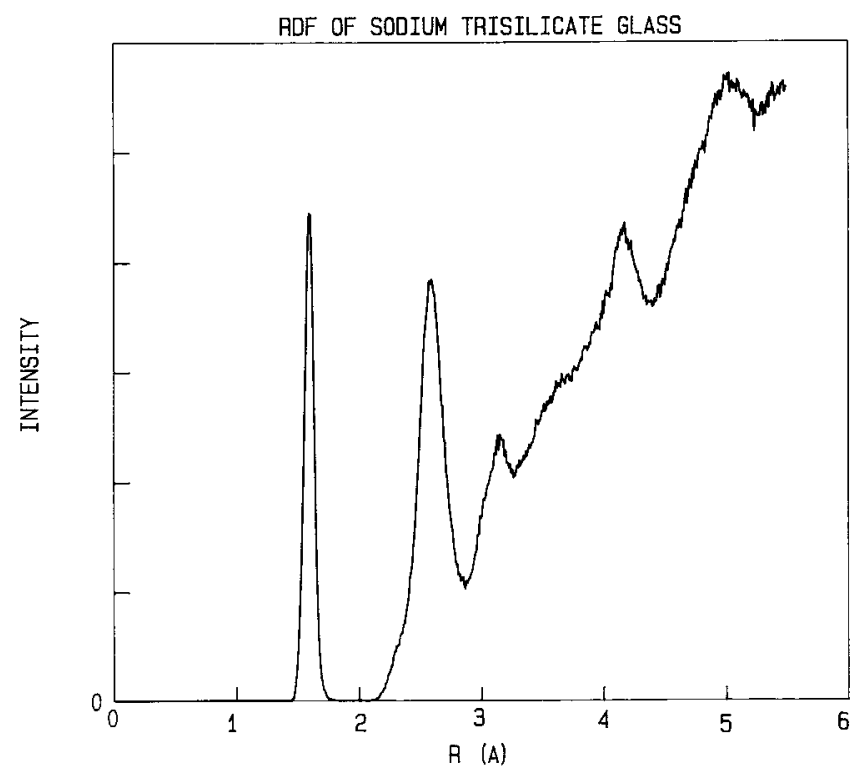

FIG. 1. Radial distribution function for simulated sodium trisilicate glass.

distance of $1.60 \mathrm{~A}$ (see Fig. 1). These tetrahedra were connected in a network structure through the sharing of bridging oxygens with neighboring tetrahedra. The bond angle distribution for the tetrahedral angle, $\phi_{\mathrm{O}-\mathrm{Si}-\mathrm{O}}$, was relatively narrow, as is shown in Fig. 2. The presence of only 4-coordinated silicon and a sharp tetrahedral angle (avg. = $109.5^{\circ} \pm 6^{\circ}$ ) indicate a high level of local order. These values are in close agreement with those found experimentally and expected from theoretical considerations. The perfect tetrahedral coordination of $\mathrm{Si}$ is a marked improvement over the previous MD studies using two-body potentials, which gave a large percentage of overcoordinated silicon. Soules ${ }^{1}$ and unpublished work by this group ${ }^{3}$ show

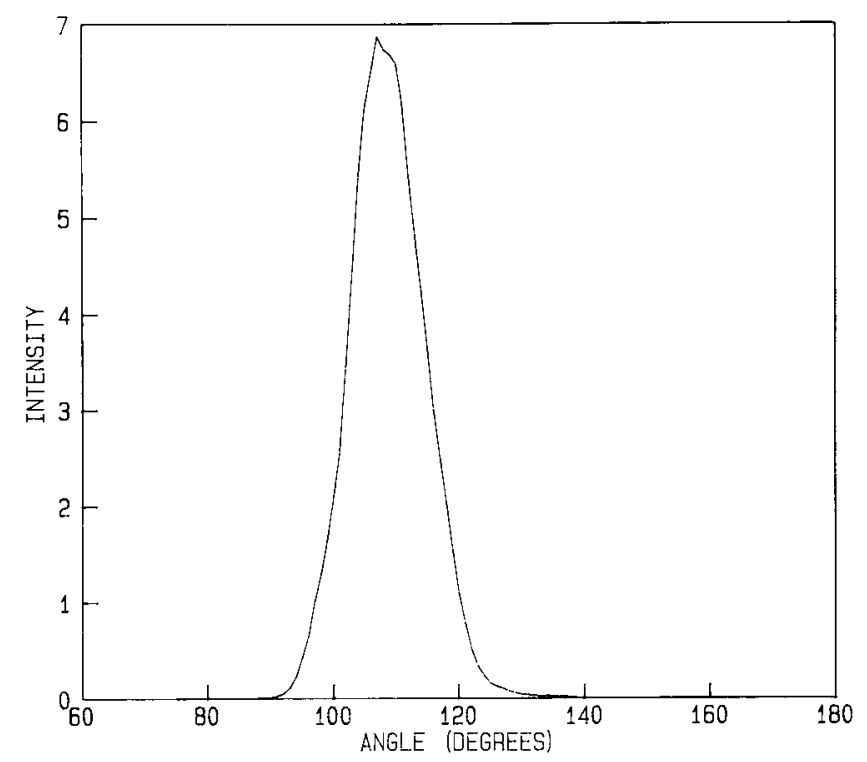

FIG. 2. $\mathrm{O}-\mathrm{Si}-\mathrm{O}$ bond angle distribution. 
TABLE II. Nearest neighbor distances and coordination numbers for several studies of sodium silicate glass.

\begin{tabular}{|c|c|c|c|c|c|c|c|}
\hline & & Si-O & $\mathrm{O}-\mathrm{O}$ & $\mathrm{Na}-\mathrm{O}$ & $\mathrm{Si}-\mathrm{Si}$ & $\mathrm{Na}-\mathrm{Si}$ & $\mathrm{Na}-\mathrm{Na}$ \\
\hline \multirow[t]{2}{*}{ This study } & $r(\AA)$ & 1.60 & 2.59 & 2.42 & 3.14 & $3.28-3.35$ & $3.03-3.13$ \\
\hline & $N$ & 4.0 & 4.8 & 5.0 & 3.7 & 6.6 & 3.6 \\
\hline \multirow[t]{2}{*}{ Soules } & $r(\AA)$ & 1.63 & 2.56 & 2.32 & 3.19 & 3.30 & 3.10 \\
\hline & $N$ & 4.4 & 5.9 & 4.5 & 4.0 & 5.1 & 3.8 \\
\hline Mozzi and & $r(\AA)$ & 1.62 & 2.65 & 2.35 & 3.12 & & \\
\hline Warren & $N$ & 4 & 6 & 6 & 4 & & \\
\hline Murray & $r(\AA)$ & 1.62 & 2.63 & 2.41 & 3.12 & 3.26 & 3.46 \\
\hline Inoue & $r(\AA)$ & 1.63 & 2.5 & 2.5 & $3.0-3.5$ & $3.0-3.5$ & \\
\hline Greaves & $r(\AA)$ & 1.61 & & 2.35 & 3.17 & & \\
\hline McKeown & $r(\AA)$ & 1.63 & & 2.2 & 3.1 & & \\
\hline \multirow[t]{2}{*}{ Misawa } & $r(\AA)$ & $1.63 \pm 0.66$ & $2.66 \pm 0.11$ & 2.4 & & & \\
\hline & $N$ & 3.9 & & 4.9 & & & \\
\hline \multirow{2}{*}{$\begin{array}{l}\text { Umes } \\
\text { (Porai) }\end{array}$} & $r(\AA)$ & & & 2.4 & & 3.2 & $3.0-4.7$ \\
\hline & $r(\AA)$ & & & & & & \\
\hline
\end{tabular}

$\mathrm{Si}-\mathrm{O}$ coordinations $>4.3$ for sodium silicate glass using pair potentials alone. Oxygen-oxygen and $\mathrm{Si}-\mathrm{Si}$ distances of $2.60 \mathrm{~A}$ and $3.14 \mathrm{~A}$, respectively (Table II), also agree reasonably well with experimental findings. Radial distribution functions for each of these showed sharp peaks, further indicating distinct local order. Feuston and Garofalini ${ }^{8}$ found similar results in their analysis of silica glass obtained from MD using the three-body potential. Optimization of parameters was not attempted for the study presented here. In the parameter search in simulations of silica, Feuston and Garofalini found that slight changes in the parameters could be used to optimize bond lengths without altering overall structures. Since the results presented here are already close to experimental data, such optimization would not alter the important result concerning the applicability of the new potential to simulate alkali silicate glasses more accurately than previous simulations.

The random network theory of glass structure proposes that while there is local order in the range of 1A$5 \mathrm{~A}$, this order is quickly lost beyond these distances. The results of this study coincide with the existence of welldefined local order and the introduction of randomness due to a broad distribution of the $\mathrm{Si}-\mathrm{O}-\mathrm{Si}$ bridging bond angle. Figure 3 shows the $\mathrm{Si}-\mathrm{O}-\mathrm{Si}$ bond angle distribution with an average $\mathrm{Si}-\mathrm{O}-\mathrm{Si}$ angle of $149^{\circ}$ and a large half width of $14^{\circ}$. In sodium silicate glasses the introduction of sodium atoms further modifies and randomizes the network structure of the $\left(\mathrm{SiO}_{4}\right)^{-4}$ tetrahedra.

The role of sodium in a silicate glass has traditionally been viewed as a network modifier. ${ }^{12}$ Figure 4 illustrates the classical interpretation of the structure of a sodium silicate glass in two dimensions. Alkali is believed to modify the network structure of a silicate glass through the creation of nonbridging oxygens virtually equaling the number of sodium atoms. The average $\mathrm{Na}-\mathrm{O}$ distance was $2.42 \mathrm{~A}$, which agrees well with the range of values shown in Table II. Sodium-silicon and $\mathrm{Na}-\mathrm{Na}$ distances were be-

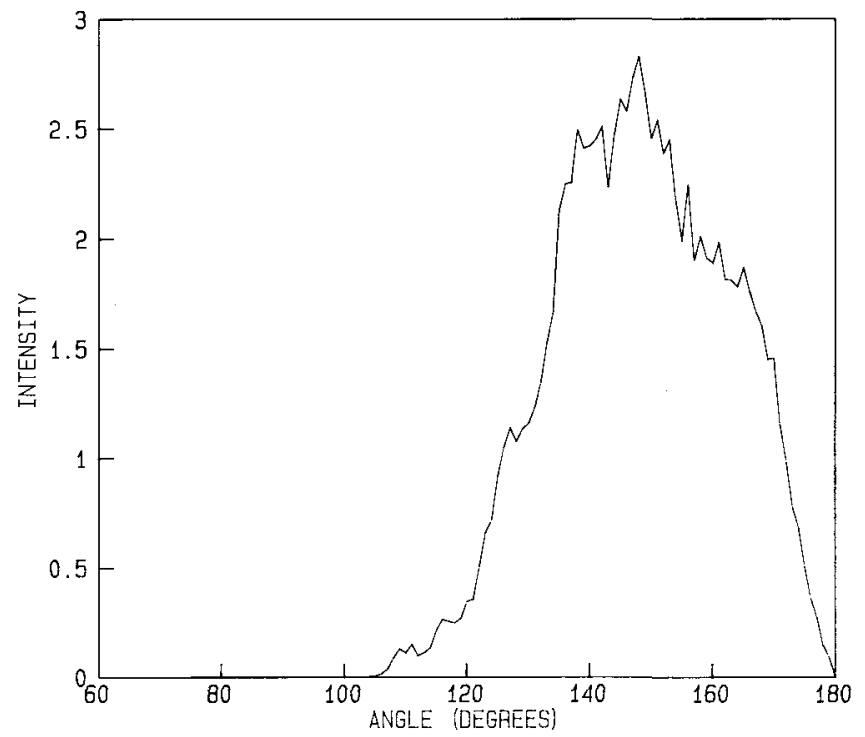

FIG. 3. $\mathrm{Si}-\mathrm{O}-\mathrm{Si}$ bond angle distribution.

tween 3.28 and $3.35 \mathrm{~A}$ and 3.03 and $3.13 \mathrm{~A}$, respectively. The RDF peaks for these atom pairs are quite broad, and thus a range of values is given rather than a distinct distance. Other findings, both experimental and simulated, also show a similarly broad peak in the same range of distances. $1,7,9,12$ The $\mathrm{Na}-\mathrm{O}$ peak was also broader than the $\mathrm{Si}-\mathrm{O}, \mathrm{O}-\mathrm{O}$, and $\mathrm{Si}-\mathrm{Si}$ peaks, though not as broad as the $\mathrm{Na}-\mathrm{Si}$ and $\mathrm{Na}-\mathrm{Na}$ peaks. This indicates a breakdown of the network structure which is associated with increasing oxygen-cation distance and the presence of the sodium atom.

\section{B. Coordination}

The subject of how atomic coordination is determined warrants some discussion. In the analysis of glass structure the coordination number is defined in practice as the average number of nearest neighbor atoms surrounding the 


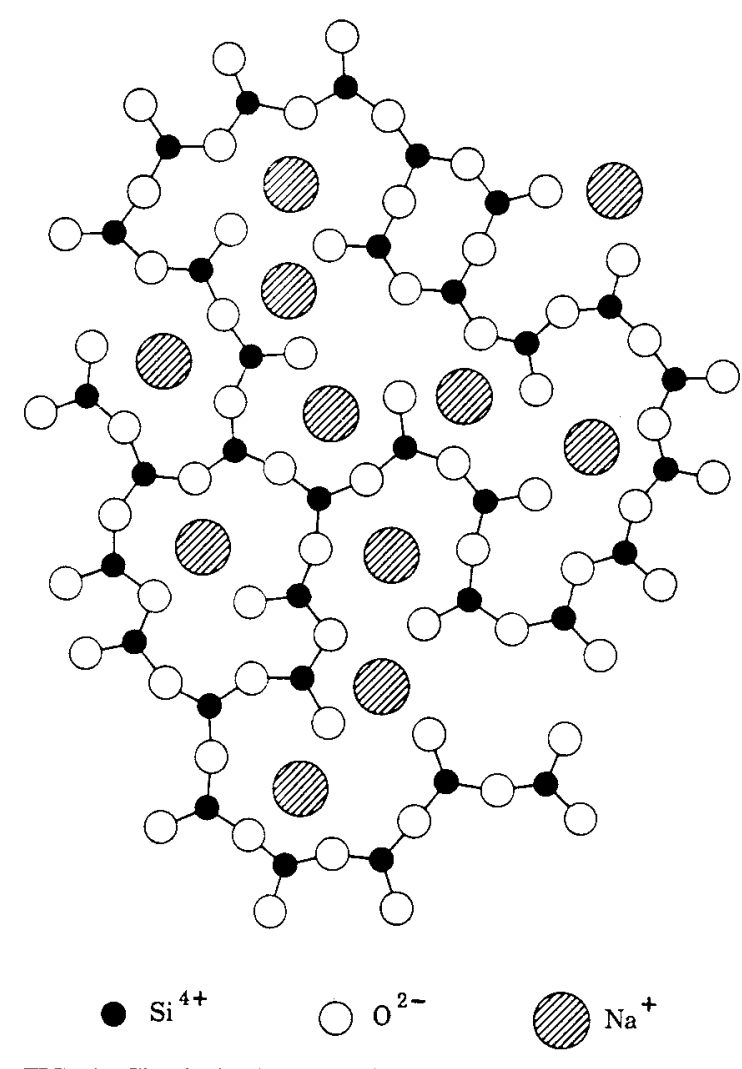

FIG. 4. Classical schematic of sodium silicate glass structure.

central atom. An atom is considered a nearest neighbor if it lies within a given radius $\left(r_{N N}\right)$ of the central atom. However, the value of $r_{N N}$ is not well defined. The cutoff, $r_{N N}$, is properly chosen as the distance corresponding to the first minimum following the first maximum in the RDF. This cutoff is easily chosen for a sharply defined peak such as the one shown for the RDF in Fig. 1. Whether $r_{N N}$ is chosen at $1.8 \mathrm{~A}$ or $2.3 \mathrm{~A}$ from this RDF, the $\mathrm{Si}-\mathrm{O}$ coordination will still be 4.0. Earlier it was stated that results of MD simulations using the two-body potential have normally reported sodium silicate glasses with $\mathrm{Si}-\mathrm{O}$ coordinations of $>4.3$ using a cutoff of $2.1 \mathrm{~A}^{1,3}$ This is a reasonable $r_{N N}$ for the Si-O RDFs presented for these results. Differing from this result, in an MD study of sodium silicates which used a two-body potential, ${ }^{6}$ Tesar and Varshneya reported an Si-O coordination of 4 for $96 \%$ of the silicon ions in the glasses studied. However, the $r_{N N}$ chosen in that study was $1.82 \mathrm{~A}$ while the tail end of the $\mathrm{Si}-\mathrm{O}$ peaks presented in their figures reached a minimum at $\sim 2.2 \mathrm{~A}$. If oxygen atoms located beyond $1.82 \mathrm{~A}$ were included in the determination of $\mathrm{Si}-\mathrm{O}$ coordination, the resultant value may have approached the normally reported coordination $>4.3$.

Determining coordination for the other atom pairs, $\mathrm{O}-\mathrm{O}$, $\mathrm{Si}-\mathrm{Si}, \mathrm{Na}-\mathrm{O}, \mathrm{Na}-\mathrm{Si}$, and $\mathrm{Na}-\mathrm{Na}$, becomes increasingly difficult due to the overlapping of first and second neighbor shells. As the nearest neighbor peak becomes wider and does not reach a distinct minimum, choosing $r_{N N}$ be- comes increasingly arbitrary. For this reason, when comparing coordination numbers it should be kept in mind that a lower $r_{N N}$ may significantly lower the coordination number (a higher $r_{N N}$ may raise the coordination number). As an example, if $r_{N N}$ for $\mathrm{O}-\mathrm{O}$ is chosen at $3.2 \mathrm{~A}$, the resulting coordination will be 7.1. However, if $r_{N N}$ is chosen at $3.0 \mathrm{~A}$, the resulting coordination will be 4.8 . Perhaps the more enlightening presentation of coordination results is in the form of a coordination vs distance curve, as presented in Fig. 5 for $\mathrm{Si}-\mathrm{O}$ pairs.

\section{Bridging oxygen to nonbridging oxygen ratio}

The analysis of nonbridging oxygen concentrations in alkali-modified silicate glasses has been the focus of several studies which employed XPS (X-ray Photoelectron Spectroscopy). ${ }^{18,19}$ It is proposed that each alkali ion will create and will be associated with a nonbridging oxygen. This suggests that nonbridging oxygens will be present in direct proportion to the concentration of alkali in a silicate glass. The ratio of the number of bridging oxygens in the glass to the number of nonbridging oxygens is expressed as a ratio, $R .{ }^{18}$ The equation which describes this expectation is given as,

$$
R=\frac{(2-3 X)}{2 X}
$$

where $X$ is the concentration of alkali oxide in the glass, $X \mathrm{Na}_{2} \mathrm{O} \cdot(1-X) \mathrm{SiO}_{2}$. Note that this equation holds true only for alkali oxide concentrations less than $33.3 \%$. If this equation is applied to sodium trisilicate glass $\left(0.25 \mathrm{Na}_{2} \mathrm{O} \cdot 0.75 \mathrm{SiO}_{2}\right)$, then the theoretically expected ratio of bridging to nonbridging oxygens is $R=2.5$.

Both Jen and Kalinowski ${ }^{18}$ and Brückner et al. ${ }^{19}$ found results using XPS which were close to theoretical expecta-

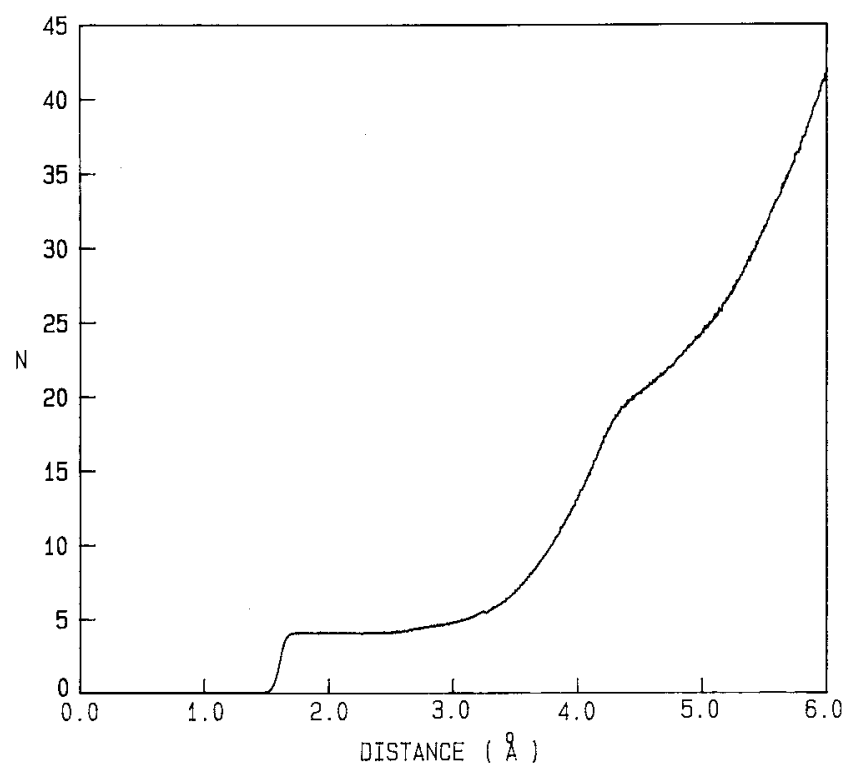

FIG. 5. Coordination number vs distance curve; number of oxygen around silicon as a function of distance. 
TABLE III. The bridging oxygen to nonbridging oxygen ratio for several studies of sodium trisilicate glass.

\begin{tabular}{lc}
\hline \hline & BO/NBO \\
\hline This study & 2.5 \\
Calculated & 2.5 \\
Jen & 2.6 \\
Brückner & 2.4 \\
\hline
\end{tabular}

tions (Table III). Bridging oxygen to nonbridging oxygen ratios of 2.6 and 2.4 were found for sodium trisilicate glass, and analysis of other concentrations of sodium silicate glass showed reasonable values as well. The results of the simulations presented here show a ratio of bridging to nonbridging oxygen of 2.5 for sodium trisilicate glass; the glass studied contained 64 sodium atoms and 65 NBOs. This result coincides with the previously described ideal model. Sodium ions were present in association with nonbridging oxygens throughout the glassy network.

\section{Q species}

The distribution of $Q_{i}$ species within the silicate glass was also determined. The $Q_{i}$ species describe the concentration of tetrahedra, $Q$, with $i$ bridging oxygen. They include $Q_{0}, Q_{1}, Q_{2}, Q_{3}$, and $Q_{4}$ species, the $Q_{0}$ having 0 bridging oxygens around a silicon, and $Q_{4}$ having 4 bridging oxygens and no nonbridging oxygens around a silicon. Each silicon tetrahedron was analyzed, and the number of bridging oxygen and nonbridging oxygen around each was determined. The glass exhibited a predominance of $Q_{4}$ and $Q_{3}$ as well as a smaller percentage of $Q_{2}$ and $Q_{1}$; no $Q_{0}$ were found (see Table IV).

Several studies have analyzed the concentration of $Q_{i}$ species in silicate glasses using magic angle spinning NMR (Nuclear Magnetic Resonance). ${ }^{20-23}$ These studies also show a predominance of $Q_{4}$ and $Q_{3}$ for sodium silicate glasses with composition less than $33.3 \%$ sodium oxide. As sodium concentration increased from $0 \%$ to $33.3 \%, Q_{3}$ species are created from $Q_{4}$ species as the sodium creates more nonbridging oxygens. At $33.3 \%$ sodium oxide, the glass has been fully converted to $Q_{3}$ and then as more $\mathrm{Na}_{2} \mathrm{O}$ is added $Q_{2}$ species are created from $Q_{3}$ species, etc. This sequence of events is expected theoretically, ${ }^{20-22}$ and is reinforced by experimental results. ${ }^{20-22}$ These results

TABLE IV. Percentage of $Q$ species in sodium trisilicate glass studied.

\begin{tabular}{cc}
\hline \hline$Q$ species & $\%$ \\
\hline$Q 0$ & 0.0 \\
$Q 1$ & 1.0 \\
$Q 2$ & 8.3 \\
$Q 3$ & 47.9 \\
$Q 4$ & 42.7 \\
\hline
\end{tabular}

predict that a sodium trisilicate glass would be $33 \% Q_{4}$ and $67 \% Q_{3}$ (no $Q_{2}, Q_{1}$, or $Q_{0}$ ). The present MD results show a more equal percentage of $Q_{4}$ and $Q_{3}$ as well as a small percentage of $Q_{2}$ and $Q_{1}$.

This may be explained in two ways. In their analysis of the NMR spectra ${ }^{20,21}$ the authors assumed that there could be only two species types present at any given alkali concentration. This assumption was based on a uniform sodium distribution in the glass, with each tetrahedron forming one nonbridging oxygen before any other tetrahedron could form two or more. Therefore, when analyzing the NMR spectra the ratio of species was calculated on the basis of only the two largest peaks (e.g., only $Q_{4}$ and $Q_{3}$ peaks were considered for $\mathrm{Na}_{2} \mathrm{O}$ concentration less than $33.3 \%$ ). This procedure automatically disallows the inclusion of lower species types as were found in the present study. Schneider, ${ }^{22}$ in an NMR study of this subject, considers the possible existence of the lower $Q_{i}$ species and allows for the existence of $5-10 \%$ of lower species types, which would coincide with our findings quite well.

The existence of lower species types also suggests the presence of sodium clustering in the network. This contradicts the previously mentioned assumption that the sodium is uniformly distributed in the glass. The location of several sodium ions near a single tetrahedron or a group of tetrahedra in the silicate structure would be expected to lead to a low $Q$ species due to the predominance of nonbridging oxygens in the region.

\section{CONCLUSION}

The addition of a three-body term to the Born-MayerHuggins two-body potential was found to increase the similarity of MD simulation results of sodium trisilicate glass with published experimental results. Nearest neighbor distances and coordination numbers coincided well with experiment. Improvement in the degree of local order occurred due to the introduction of bond directionality through the addition of the three-body term. Silicon coordination was consistent at 4.0 and the tetrahedral angle was sharpened in comparison to molecular dynamics results which used only two-body potentials. Concentrations of $Q_{i}$ species and the ratio of bridging oxygen to nonbridging oxygen also compared reasonably with theoretically expected and experimentally determined results. Although the silicate glass displayed a modified network structure due to structural break-up caused by the sodium ions, the glass maintained a high level of local order at the level of the silicon tetrahedron. Thus, the application of a threebody potential in MD simulations of multi-component silicate glasses proved to be encouraging.

\section{ACKNOWLEDGMENTS}

The authors wish to acknowledge the support of the Center for Ceramics Research-Rutgers University, the Fiber Optics Material Research Program-Rutgers University, 
and the Army Research Office, grant no. DAAL03-86-K0047. One of the authors (RGN) conducted research under the auspices of the Henry Rutgers Scholars Program. SG acknowledges partial support from the Pacific Northwest Laboratory under United States DOE, OBES, contract number DE AC06-76RLO-1830.

\section{REFERENCES}

${ }^{1}$ T. F. Soules, "A Molecular Dynamic Calculation of the Structure of Sodium Silicate Glasses," J. Chem. Phys. 71 [11], 4570 (1979).

${ }^{2}$ S. H. Garofalini, "A Molecular Dynamics Simulation of the Vitreous Silica Surface," J. Chem. Phys. 78 [4], 2069 (1983).

${ }^{3}$ R. G. Newell and S. H. Garofalini, unpublished work.

${ }^{4} \mathrm{~S}$. H. Garofalini, "Behavior of Atoms at the Surface of a $\mathrm{K}_{2} \mathrm{O} \cdot 3 \mathrm{SiO}_{2}$ Glass - A Molecular Dynamics Simulation,"J, Am. Ceram. Soc. 67 [2], 133 (1984).

${ }^{5}$ S. H. Garofalini and S. M. Levine, "Differences in Surface Behavior of Alkali Ions in $\mathrm{Li}_{2} \mathrm{O} \cdot 3 \mathrm{SiO}_{2}$ and $\mathrm{Na}_{2} \mathrm{O} \cdot 3 \mathrm{SiO}_{2}$ Glasses," J. Am. Ceram. Soc. 68 [7i], 376 (1985).

${ }^{6}$ A. A. Tesar and A. K. Varshneya, "Molecular Dynamics Simulation of Alkali-Silicate Glass Structures," J. Chem. Phys. 87 [5], 2986 (1987).

${ }^{7}$ S. K. Mitra and R. W. Hockney, "A Molecular Dynamics Simulation of the Structure of Soda Silica," Philos. Mag. 48 [2] (1983).

${ }^{8}$ B. P. Feuston and S. H. Garofalini, "Empirical Three-Body Potential for Vitreous Silica," J. Chem. Phys. 89, 5818 (1988).

${ }^{9}$ R. A. Murray, L. W. Song, and W. Y. Ching, "Structural Models for $\left(\mathrm{Na}_{2} \mathrm{O}\right)_{x}\left(\mathrm{SiO}_{2}\right)_{1-x}$ Glasses with Periodic Boundaries," J. Non-Cryst. Solids 94, 133 (1987).

${ }^{10}$ R. L. Mozzi and B. E. Warren, "Structure of Vitreous Silica," J. Appl. Crystallogr. 2, 164 (1969).

${ }^{11}$ B. E. Warren and J. Biscoe, "Fourier Analysis of X-Ray Patterns of Soda-Silica Glasses," J. Am. Ceram. Soc. 21, 49 (1939).

${ }^{12}$ E. A. Porai-Koshits, "Proceedings of a Conference on the Structure of Glass," J. Non-Cryst. Solids 25, 87 (1977).

${ }^{13}$ I. Yasui, H. Hasegawa, and M. Imaoka, "X-Ray Diffraction Study of the Structure of Silicate Glasses. Part 1. Alkali Metasilicate Glasses," Phys. Chem. Glass 24 [3], 65 (1983).
${ }^{14}$ M. Imaoka, H. Hasegawa, and I. Yasui, "X-Ray Diffraction Study of the Structure of Silicate Glasses. Part 2. Alkali Disilicate Glasses," Phys. Chem. Glass 24 [3], 72 (1983).

${ }^{15}$ G. N. Greaves, A. Fontaine, P. Lagarde, D. Raoux, and S. J. Gurman, "Local Structure of Silicate Glasses," Nature 293, 611 (1981).

${ }^{16}$ D. A. McKeown, G. A. Waychunas, and G. E. Brown, Jr., "EXAFS and XANES Study of the Local Coordination Environment of Sodium in a Series of Silica-rich Glasses and Selected Minerals within the $\mathrm{Na}_{2} \mathrm{O}-\mathrm{Al}_{2} \mathrm{O}_{3}-\mathrm{SiO}_{2}$ System," J. Non-Cryst. Solids 74, 325 (1985).

${ }^{17}$ M. Misawa, D. L. Price, and K. Suzuki, "The Short-Range Structure of Alkali Disilicate Glasses by Pulsed Neutron Total Scattering," J. NonCryst. Solids 37, 85 (1980).

${ }^{18}$ J. S. Jen and M. R. Kalinowski, "An ESCA Study of the Bridging to Nonbridging Oxygen Ratio in Sodium Silicate Glass and the Correlations to Glass Density and Refractive Index," J. Non-Cryst. Solids 38 and 39, 21 (1979).

${ }^{19}$ R. Brückner, Hans-Ulrich Chun, and Hans Goretzki, "Photoelectron Spectroscopy (ESCA) on Alkali Silicate and Soda Aluminosilicate Glass," Glastechn. Ber. 51, 1 (1978).

${ }^{20}$ R. Dupree, D. Holland, and D. S. Willims, "The Structure of Binary Alkali Silicate Glasses," J. Non-Cryst. Solids 81, 185 (1986).

${ }^{21}$ R. Dupree, D. Holland, P. W. McMillan, and R. F. Pettifer, "The Structure of Soda-Silica Glasses: A MAS NMR Study," J. Non-Cryst. Solids 81, 185 (1986).

${ }^{22}$ E. Schneider, J. F. Stebbins, and A. Pines, "Speciation and Local Structure in Alkaline and Alkaline Earth Silicate Glasses: Constraints from Si NMR Spectroscopy," J. Non-Cryst. Solids 89, 371 (1987).

${ }^{23}$ J. B. Murdoch, J. F. Stebbins, and I. S. E. Carmichael, "High-Resolution ${ }^{29}$ Si NMR Study of Silicate and Aluminosilicate Glasses: The Effect of Network-Modifying Cations," Am. Min. 89, 371 (1987).

${ }^{24}$ S. H. Garofalini and H. Melman, Better Ceramics through Chemistry, edited by J. Brinker, D. Clark, and D. Ulrich (Materials Research Society, Pittsburgh, PA, 1986), p. 73.

${ }^{25}$ S. H. Garofalini, Structure and Bonding in Non-Crystalline Solids, edited by G. E. Walrefen and A. G. Revesz (Plenum, New York, 1986).

${ }^{26}$ O. V. Mazurin, M. V. Streltsina, and T. P. Shvaiko-Shvaikoskaya, Handbook of Glass Data, Part A (Physical Sciences Data, Elsevier, New York, 1983), p. 15. 